\title{
Pharmacologic Manipulation of Human Erythrocyte 2,3-Diphosphoglycerate Levels by Prednisone Administration
}

\author{
ALAN B. SILKEN
}

Yale University School of Medicine, Department of Pediatrics, New Haven, Connecticut, USA

\section{Extract}

Erythrocyte 2,3-diphosphoglycerate (2,3-DPG) concentrations in 10 patients with acute lymphoblastic leukemia rose $21.3 \%(P<0.02)$ after 3 weeks of prednisone and vincristine therapy, and returned to pretreatment level 2 weeks after therapy had been discontinued. The mean 2,3-DPG level of three patients on vincristine alone did not vary significantly from the control level of the leukemia patients on prednisone and vincristine. No significant change in serum inorganic phosphate level was observed.

The mean erythrocyte 2,3-DPG concentration of 17 nephrotic syndrome patients being treated with chronic prednisone therapy was $14.0 \%$ higher than a control group of 20 nephrotic syndrome patients not being treated with prednisone $(P<0.01)$. A significant positive correlation was observed between the dose of prednisone and 2,3-DPG level.

\section{Speculation}

Human erythrocyte 2,3-DPG concentrations may be manipulated by pharmacologic doses of prednisone. Prednisone therapy may therefore be of potential benefit in clinical conditions characterized by decreased oxygen delivery to tissues.

It has been well documented that 2,3-DPG plays a significant role in hemoglobin-oxygen affinity $(3,8)$, and studies have shown that an elevation in 2,3-DPG levels results in a shift of the hemoglobin-oxygen dissociation curve to the right, which increases the $\mathrm{P}_{50}\left(\mathrm{P}_{\mathrm{O}_{2}}\right.$ at $50 \%$ saturation), and result in increased release of oxygen to the tissues (4).

Many studies have shown the response of 2,3-DPG to physiologic stresses. In conditions characterized by increased oxygen consumption or decreased oxygen supply to tissues, 2,3-DPG levels have been found to be elevated facilitating release of oxygen to tissues. Significantly elevated 2,3-DPG levels have been observed in patients with anemia (22), chronic lung disease (13), and cyanotic heart disease (14).

Although it has been demonstrated that a right-shifted hemoglobin-oxygen dissociation curve can be beneficial in certain clinical conditions (15), relatively little work has been done on the manipulation of hemoglobin-oxygen affinity by pharmacologic agents.

Pharmacologically induced increases in erythrocy te 2,3-DPG concentrations have been demonstrated in stored blood (17) and in rhesus monkeys (21) treated with inosine, pyruvate, and inorganic phosphate solutions. Elevations in 2,3-DPG levels have also been observed in a study of six patients with chronic renal failure treated with androgen for 12 weeks (18). Another report has shown elevated 2,3-DPG levels in rhesus monkeys treated with testosterone, but no similar elevation with estradiol (9). Aldosterone- and cortisol-induced decreases in hemoglobin-oxygen affinity have been observed in rabbits, but 2,3-DPG levels were not measured (2). Elevated 2,3-DPG concentrations have also been found in hyperthyroidism (12). Other studies have shown that propanolol shifts the hemoglobin-oxygen dissociation curve to the right, but there is no corresponding increase in total erythrocyte 2,3-DPG concentration associated with this effect $(16,19)$. There have not been any reports of the effects of corticosteroids on human erythrocyte 2,3-DPG concentration.

\section{METHODS AND MATERIALS}

Erythrocyte 2,3-DPG concentrations were determined employing the Sigma Chemical Company kit $(23,25)$ on heparinized blood that was kept at $0-4^{\circ}$ during transport to the laboratory. The assay was done using the stoichiometric conversion of 2,3-DPG to glyceraldehyde 3-phosphate and oxidation of NADH to NAD according to the method of Keitt (10). Hemoglobin was assayed as the cyanomethemoglobin derivative, and hematocrit was determined by microcentrifugation. Serum inorganic phosphate concentrations were determined by automated analysis by the Clinical Laboratories of the Yale-New Haven Hospital (26). pH determinations were done using the Radiometer PHM 71 acid-base analyzer (27). The Student $t$ test was used to determine the degree of significance of the changes observed. Significance limits for correlations were determined by calculation of the correlation coefficients.

Two groups of pediatric out-patients being treated with corticosteroids were studied. No smokers or patients with respiratory disease, anemia, or other condition known to alter hemoglobin-oxygen affinity or 2,3-DPG levels were studied. Informed consent was obtained before blood samples were taken.

Group I consisted of 6 girls and 4 boys with a mean age of 6 years. All had acute lymphoblastic leukemia which was in complete remission. All were on maintenance therapy (methotrexate, cytoxan, cytosine arabinoside) just before the study. At the time of the study, they were undergoing "elective reinduction." Maintenance therapy was discontinued, and prednisone $(1.5-2.2 \mathrm{mg} / \mathrm{kg} / 24 \mathrm{hr}$ orally) and vincristine $(1.5$ $\mathrm{mg} / \mathrm{m}^{2} /$ week intravenously) were given for 3 weeks, followed by 1 week of steroid tapering. Venous blood samples were obtained by venipuncture before, during, and at least 2 weeks after prednisone was discontinued and maintenance therapy had been resumed. Blood samples were also obtained from two patients receiving chronic vincristine therapy, and one patient who was electively reinduced with 3 weekly doses of vincristine alone.

Group II consisted of 17 patients with nephrotic syndrome 
(mean age $=8$ years) who were being treated with prednisone $(0.1-2.3 \mathrm{mg} / \mathrm{kg} / 24 \mathrm{hr}$ orally). The duration of continuous prednisone treatment ranged from $1-10$ months (mean $=4.8$ months). The control group consisted of 20 patients (mean age $=10.9$ years) with nephrotic syndrome who had not been treated with corticosteroids for at least 3 weeks before the study.

\section{RESULTS}

Erythrocyte 2,3-DPG concentration increased in all of the acute leukemia patients (group $I$ ) during prednisone therapy. The mean 2,3-DPG level rose $21.3 \%$ after 3 weeks of therapy, which was a significant increase $(P<0.02)$, and returned to pretreatment levels 2 weeks after therapy had been discontinued (Fig. 1). The mean \pm SEM for erythrocyte 2,3-DPG, serum inorganic phosphate, hematocrit, and hemoglobin before, during and after therapy are compared with the data for the patients on vincristine alone on Table 1 . The mean 2,3-DPG level of the three patients on vincristine alone did not vary significantly from the control level of the leukemia patients on prednisone and vincristine. The mean serum inorganic phosphate level initially fell during prednisone administration, and then returned to pretreatment level when therapy was discontinued. As shown on Figure 2, the mean hematocrit level rose from $37.1 \%$ to $41.9 \%(P<0.005)$, and the mean hemoglobin level rose from $12.8 \mathrm{~g} / 100 \mathrm{ml}$ to 13.1 $\mathrm{g} / 100 \mathrm{ml}$ (not significant) during prednisone therapy, and returned to pretreatment level after therapy was discontinued.

In the nephrotic syndrome patients (group $I I$ ), the 2,3-DPG concentration of the prednisone-treated patients was $14.0 \%$ higher than the untreated patients, a significant difference $(P$ $<0.01$ ), as tabulated in Table 2. As shown in Figure 3, there was a significant positive correlation between the dose of prednisone and 2,3-DPG level $(\mathrm{r}=0.611, P<0.01)$. Upon analysis of the data, it was found that four patients had high 2,3-DPG levels at relatively low prednisone doses, and three of these patients were the only prednisone-treated patients who had proteinuria at the time of blood sampling ( $\bullet$, Fig. 3). When these three patients were excluded from analysis, the correlation between dose of prednisone and 2,3-DPG level was even more significant, as shown by the broken line in Figure 3 ( $\mathrm{r}=0.786, P<0.001)$. There was no significant difference between 2,3-DPG levels of patients with and without proteinuria in either the treated or the untreated groups.

Mean hematocrit was $44.4 \%$ in the prednisone-treated group, and $38.6 \%$ in the control patients, which was a significant difference $(P<0.005)$. There was no significant difference in mean $\mathrm{pH}$ of the treated and control patients. In both the acute leukemia patients (group $I$ ) and the nephrotic syndrome patients (group II), no significant differences in erythrocyte 2,3-DPG concentrations were noted between males and females.

\section{DISCUSSION}

This study provides the first reported evidence of a significant dose-related pharmacologic manipulation of 2,3DPG concentrations in human erythrocytes by acute and chronic prednisone administration.

Studies have shown that elevations of serum inorganic phosphate may cause increased erythrocyte 2,3-DPG concentrations $(7,11)$. We cannot attribute the action of prednisone to this mechanism since serum inorganic phosphate levels initially fell while 2,3-DPG levels started to rise, as has also been observed by other researchers $(18,24)$. In patients with low 2,3-DPG levels secondary to transfusions during cardiac surgery, Young et al. (24) have proposed that decreased serum inorganic phosphate levels after initiation of resynthesis of 2,3-DPG may be due to accelerated utilization of plasma inorganic phosphates in the synthesis of organic phosphates.

It has also been shown that alkalosis may increase

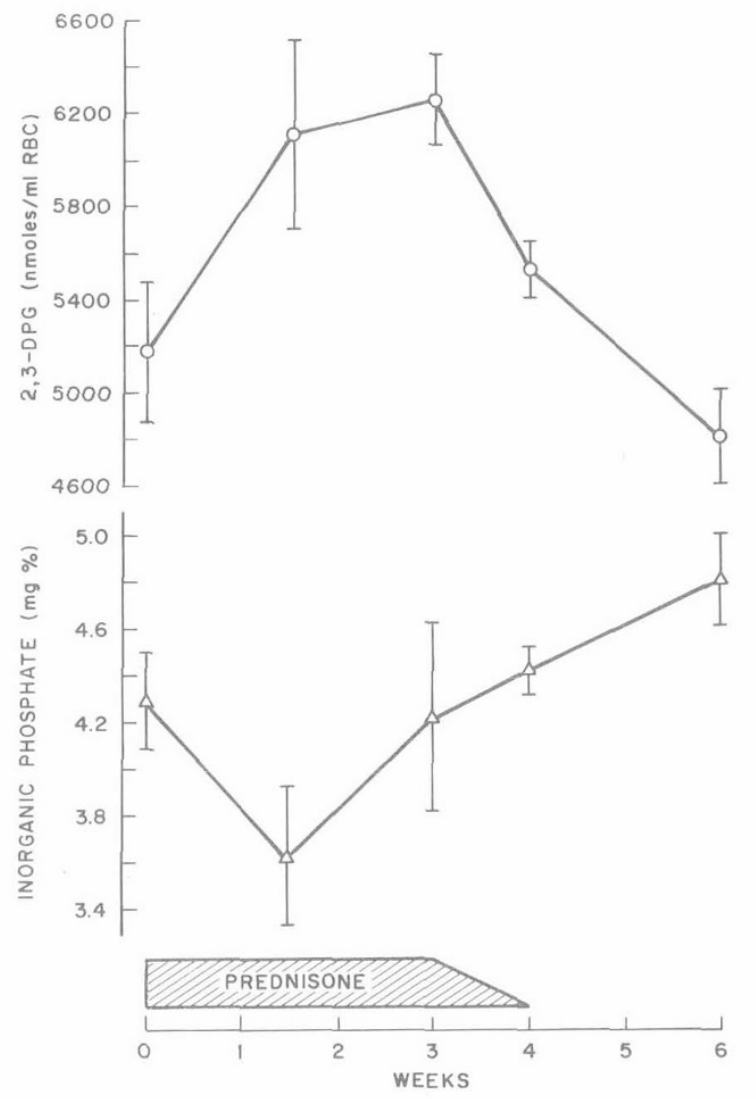

Fig. 1. Effect of prednisone on 2,3-diphosphoglycerate (2,3-DPG) and inorganic phosphate levels in acute leukemia patients (group I).

Table 1. Acute prednisone therapy ${ }^{1}$

\begin{tabular}{|c|c|c|c|c|c|c|}
\hline & \multirow[b]{2}{*}{$\begin{array}{l}\text { Vincristine } \\
\text { only }\end{array}$} & \multicolumn{5}{|c|}{ Prednisone + vincristine } \\
\hline & & $\begin{array}{l}\text { Before } \\
\text { therapy }\end{array}$ & $1-2$ Weeks on & 3 Weeks on & 1 Week taper & 2 Weeks off \\
\hline 2,3-DPG ( $\mathrm{nmol} / \mathrm{ml} \mathrm{RBC})$ & $4,879 \pm 91$ & $5,182 \pm 316$ & $6,092 \pm 439$ & $\dot{6}, 286 \pm 189$ & $5,509 \pm 77$ & $4,815 \pm 199$ \\
\hline $\begin{array}{l}\text { Inorganic phosphate } \\
(\mathrm{mg} / 100 \mathrm{ml})\end{array}$ & $3.8 \pm 0.3$ & $4.3 \pm 0.2$ & $3.6 \pm 0.3$ & $4.2 \pm 0.4$ & $4.4 \pm 0.1$ & $4.8 \pm 0.2$ \\
\hline Hematocrit $(\%)$ & $41.3 \pm 1.4$ & $37.1 \pm 0.6$ & $39.7 \pm 1.1$ & $41.9 \pm 1.1$ & $40.0 \pm 2.9$ & $37.3 \pm 1.3$ \\
\hline Hemoglobin $(\mathrm{g} / 100 \mathrm{ml})$ & $14.1 \pm 0.6$ & $12.8 \pm 0.2$ & $13.0 \pm 0.2$ & $13.1 \pm 0.3$ & $12.9 \pm 0.5$ & $12.2 \pm 0.4$ \\
\hline
\end{tabular}

\footnotetext{
${ }^{1}$ Values represent mean \pm SEM. RBC: red blood cells.
} 


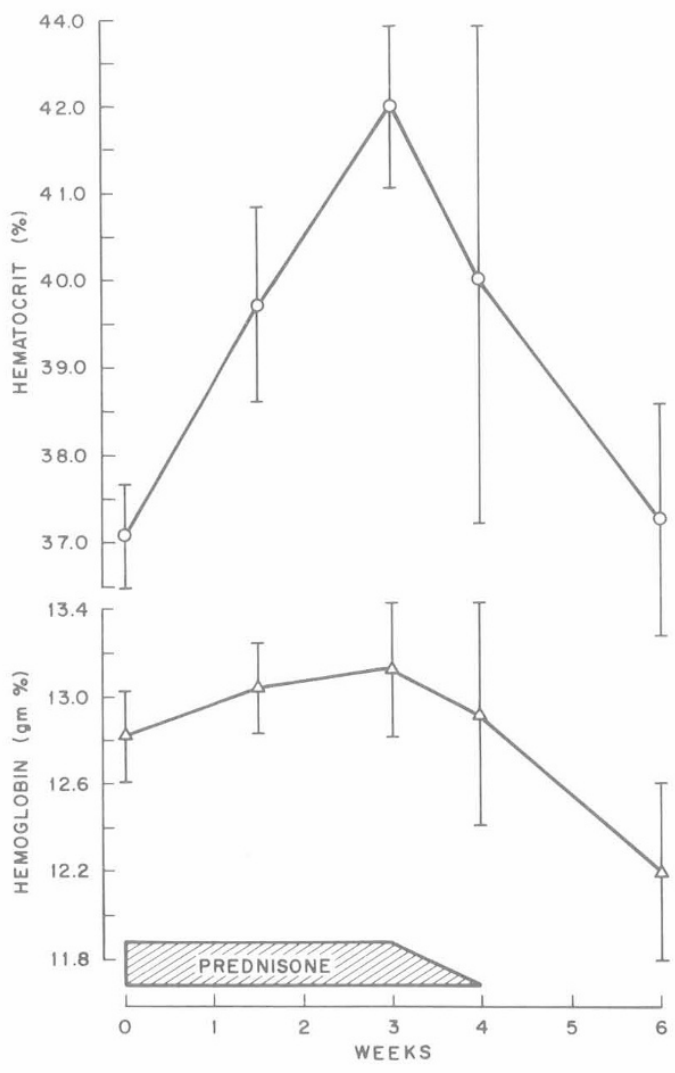

Fig. 2. Effect of prednisone on hematocrit and hemoglobin levels in acute leukemia patients (group I).

Table 2. Chronic prednisone therapy

\begin{tabular}{lcccc}
\hline & Control & Treated & $P$ & Increase \% \\
\hline $\begin{array}{l}\text { 2,3-DPG } \\
\left(\mathrm{nmol} / \mathrm{ml} \mathrm{RBC}^{2}\right)\end{array}$ & $4,527 \pm 146$ & $5,162 \pm 213$ & $<0.01$ & 14.0 \\
$\begin{array}{l}\text { Hematocrit }(\%)^{1} \\
\mathrm{pH}^{3}\end{array}$ & $38.6 \pm 1.4$ & $44.4 \pm 0.8$ & $<0.005$ & 15.0 \\
\hline
\end{tabular}

${ }^{1}$ Mean \pm SEM

${ }^{2}$ Red blood cells.

${ }^{3}$ Mean.

${ }^{4}$ Not significant.

erythrocyte 2,3-DPG concentrations (1). However, $\mathrm{pH}$ determinations done in the nephrotic syndrome patients were not significantly different in the treated and untreated groups.

The elevations in hematocrit and hemoglobin which occurred during prednisone therapy confirm the known erythropoietic stimulus of corticosteroids $(5,6)$, and provide evidence that the observed rise in 2,3-DPG levels was not a response to anemia.

Since the 2,3-DPG level of the patients on vincristine alone remained within the control level, the elevation in erythrocyte 2,3-DPG concentration was due only to prednisone therapy.

Studies have shown that triiodothyronine directly stimulates 2,3-DPG synthesis by activation of DPG mutase (20). Although the mechanism of action of prednisone in this study is not entirely elucidated by the data presented, prednisone may act by increasing erythrocyte glycolysis, specific enzyme induction, or increasing tissue oxygen consumption. This study did not examine the rapidity with which the observed rise in erythrocy te 2,3-DPG level occurred.

Although $\mathrm{P}_{50}$ values were not directly measured in the present study, it has been shown that an increase in 2,3-DPG concentration of $430 \mathrm{nmol} / \mathrm{ml}$ erythrocyte shifts the hemoglobin-oxygen dissociation curve approximately $1 \mathrm{~mm} \mathrm{Hg}$ to the right (14). The average elevation in the acute leukemia patients was $1,103 \mathrm{nmol}$, and in the nephrotic syndrome patients was $635 \mathrm{nmol}$. A 2-mm shift of the dissociation curve to the right would increase the extraction of oxygen from hemoglobin from 5.5 volumes/100 liter to 6.5 volumes/100 liter and would provide approximately $20 \%$ more oxygen delivery to the tissues (Fig. 4). This increase combined with a 5\% higher hematocrit and a $2 \%$ increase in hemoglobin would provide an effective increase in oxygen delivery to tissues of approximately $25 \%$ at a capillary end-oxygen tension of $40 \mathrm{~mm} \mathrm{Hg}$.

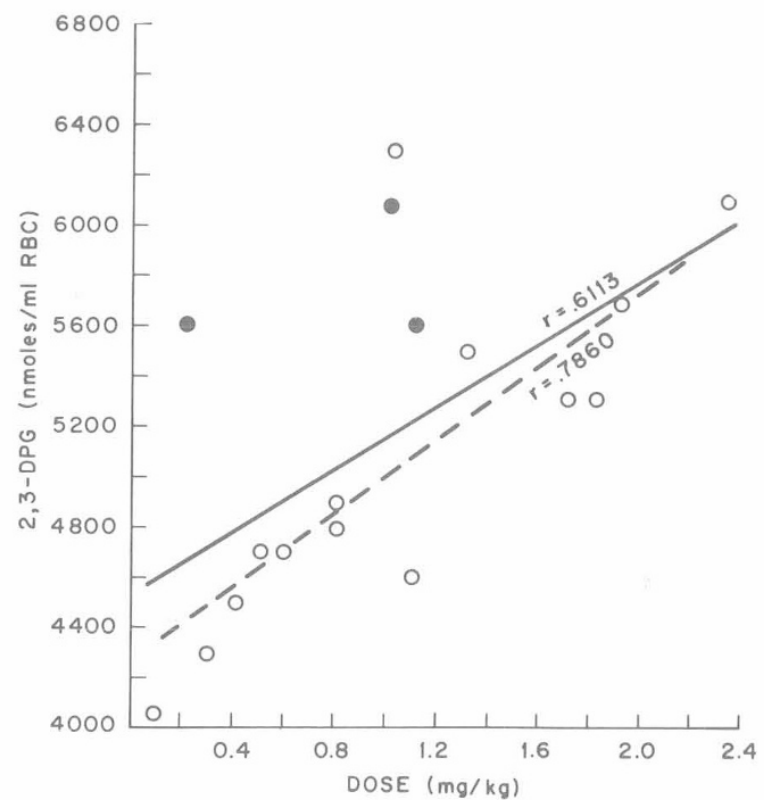

Fig. 3. Correlation between 2,3-diphosphoglycerate (2,3-DPG) level and dose of prednisone in nephrotic syndrome patients (group II). The solid line (-) represents the correlation for all prednisone-treated patients $(\mathrm{r}=0.6113, p<0.01)$. The three solid circles $(\bullet)$ represent patients with proteinuria, the open circles (0) represent patients without proteinuria, and the broken line (- - ) shows the correlation only for patients without proteinuria $(\mathrm{r}=0.7860, P<0.001)$.

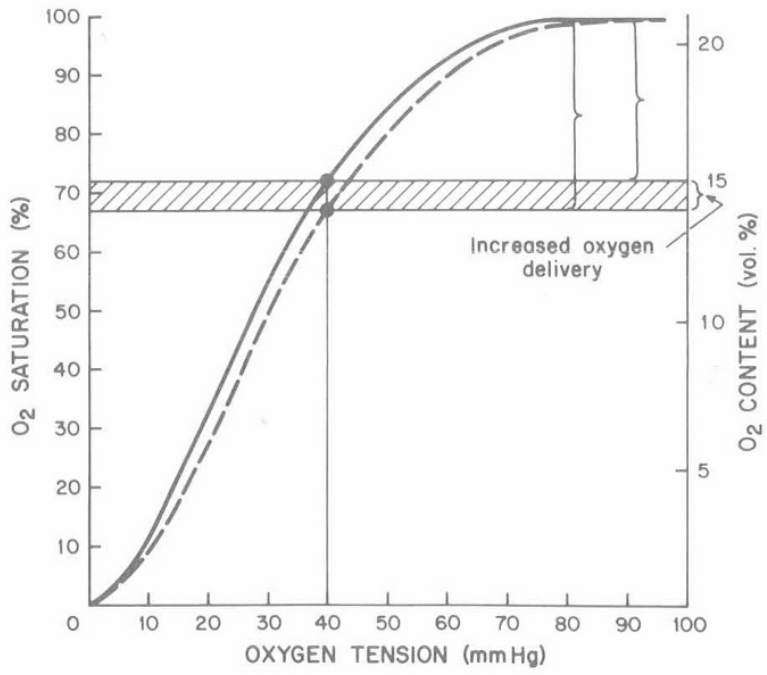

Fig. 4. Shifting the curve $2 \mathrm{~mm} \mathrm{Hg}$ to the right (- - ) allows the oxygen extraction from hemoglobin to increase to 6.5 volumes $/ 100 \mathrm{ml}$ at an oxygen tension of $40 \mathrm{~mm} \mathrm{Hg}$. Normal oxygen extraction is about 5.5 volumes $/ 100 \mathrm{ml}$. The increased release of oxygen allows about $20 \%$ more oxygen delivery to the tissues. 


\section{SUMMARY}

Significant dose-related elevations in 2,3-DPG levels were observed in acute leukemia patients on acute prednisone therapy and in nephrotic syndrome patients on chronic prednisone therapy. The elevation in 2,3-DPG levels could not be explained on the basis of changes in serum inorganic phosphate, hematocrit, or hemoglobin levels. It is suggested that the mechanism of action of prednisone may be increased erythrocyte glycolysis, specific enzyme induction, or increased tissue oxygen consumption. These data indicate that 2,3-DPG levels in human erythrocytes can be pharmacologically manipulated by prednisone administration.

\section{REFERENCES AND NOTES}

1. Astrup, P.: Red cell pH and oxygen affinity of hemoglobin. New Engl. J. Med., 283: 202 (1970).

2. Bauer, C., and Rathschleg-Schaefer, A. M.: Influence of aldosterone and cortisol on oxygen affinity and cation concentration of blood. Resp. Physiol., 5: 360 (1968).

3. Benesch, R., and Benesch, R. E.: The effect of organic phosphates from the human erythrocyte on the allosteric properties of hemoglobin. Biochem. Biophys. Res. Commun., 26: 162 (1967).

4. Benesch, R., Benesch, R. E., and Yu, C. I.: Reciprocal binding of oxygen and diphosphoglycerate by human hemoglobin. Proc. Nat. Acad. Sci. U. S. A., 59: 526 (1968).

5. Borsook, H.: Two inducers of rapid erythroblast multiplication in vitro. Nature 230: 328 (1971).

6. Byron, J. W.: Effect of steroids and dibutyryl cyclic AMP on the sensitivity of haemopoietic stem cells to ${ }^{3} \mathrm{H}$-thymidine in vitro. Nature, 234: 39 (1971).

7. Card, R. T., and Brain, M. C.: The "anemia" of childhood: Evidence for a physiologic response to hyperphosphatemia. New Engl. J. Med., 288: 388 (1973).

8. Chanutin, A., and Curnish, R. R.: Effect of organic and inorganic phosphates on the oxygen equilibrium of human erythrocytes. Arch. Biochem., 121: 96 (1967).

9. Desai, J. N., Rao, L. M., Gunther, S., and Shahidi, N. T.: The effects of steroid hormones on erythocyte 2,3-diphosphoglycerate (Abstract). Pediat. Res., 7: 354/126 (1973).

10. Keitt, A. S.: Reduced NADP linked analysis of 2,3-diphosphoglycerate: Spectrophotometric and fluorometric procedures. Lab. Methods, 77: 470 (1972).

11. Lichtman, M. A., and Miller, D. R.: Erythrocyte glycolysis, 2,3-diphosphoglycerate and adenosine triphosphate concentrations in uremic subjects: Relationship to extracellular phosphate concentration. J. Lab. Clin. Med., 76: 267 (1970).

12. Miller, L. D., Sugerman, H. J., Miller, W. W., Delivoria-Papadopoulos, M., Dianco, J. F., Gottlieb, A. J., and Oski, F. A.: Increased peripheral oxygen delivery in thyrotoxicosis: Role of red cell 2,3-diphosphoglycerate. Ann. Surg., 172: 1051 (1970).

13. Oski, F. A., Gottlieb, A. J., Delivoria-Papadopoulos, M., and Miller, W. W.: Red cell, 2,3-diphosphoglycerate levels in subjects with chronic hypoxemia. New Eng1. J. Med., 280: 1165 (1969).

Copyright (c) 1975 International Pediatric Research Foundation, Inc.
14. Oski, F. A., Gottlieb, A. J., Miller, W. W., and Delivoria-Papadopoulos, M. The effects of deoxygenation of adult and fetal hemoglobin on the synthesis of red cell 2,3-diphosphoglycerate and its in vivo consequences. J. Clin. Invest., 49: 400 (1970).

15. Oski, F. A., Marshall, B. E., Cohen, P. J., Sugerman, H. J., and Miller, L. D.: Exercise with anemia: The role of the left or right shifted oxygen-hemoglobin equilibrium curve. Ann. Int. Med., 74: 44 (1971).

16. Oski, F. A., Miller, L. D., Delivoria-Papadopoulos, M., and Shelbourne, J. C.: Changes induced in vivo by propanolol. Science, 175: 1372 (1972).

17. Oski, F. A., Sugerman, H. J., and Miller, L. D.: Experimentally induced alterations in the affinity of hemoglobin for oxygen. I. In vitro restoration of erythrocyte 2,3-diphosphoglycerate and its relationship to erythrocyte purine nucleoside phosphorylase activity in a variety of species. Blood, 39: 522 (1972).

18. Parker, J. P., Beirne, G. J., Desai, J. N., Raich, P. C., and Shahidi, N. T.: Androgen-induced increase in red cell 2,3-diphosphoglycerate. New Engl. J. Med., 287: 581 (1972).

19. Pendleton, R., Newman, D. J., Sherman, S., Brann, E., and Maya, W.: Effect of propanolol upon the hemoglobin-oxygen dissociation curve. J. Pharmacol. Exp. Ther., 180: 647 (1972).

20. Snyder, L. M., and Reddy, W. J.: Mechanism of action of thyroid hormones on erythrocyte 2,3-diphosphoglyceric acid synthesis. J. Clin. Invest., 49: 1993 (1970).

21. Sugerman, H. J., Pollock, T. W., Rosato, E. F., Delivoria-Papadopoulos, M., Miller, L. D., and Oski, F. A.: Experimentally induced alterations in the affinity of hemoglobin for oxygen. II. In vivo effect of inosine, pyruvate, and phosphate on oxygen hemoglobin affinity in rhesus monkeys. Blood, 39: 524 (1972).

22. Torrance, J., Jacobs, P., Lenfant, C., and Finch, C.: Intraerythrocytic adaptation to anemia. New Engl. J. Med., 283: 165 (1970).

23. UV Determination of 2,3-Diphosphoglycerate in Blood at $340 \mathrm{~m} \mu$. Bulletin No. 25, Sigma Chemical Co., St. Louis, Mo.

24. Young, J. A., Lichtman, M. A., and Cohen, J.: Reduced red cell 2,3-diphosphoglycerate and adenosine triphosphate, hypophosphatemia and increased hemoglobin-oxygen affinity after cardiac surgery. Circulation, 47: 1313 (1973).

25. Beckman DU-2 spectrophotometer, Beckman Instruments, Inc., Palo Alto, Calif.

26. New Haven, Conn.

27. Radiometer Electronik Measuring Instruments, Copenhagen, Denmark.

28. The author wishes to express his appreciation to Dr. Howard A. Pearson, Dr. Norman J. Siegel, and Dr. David Seligson for their valuable guidance and assistance.

29. Some of the patients were studied in the Children's Clinica Research Center, supported by United States Public Health Service Grant RR-00125 Division of Research Resources, National Institutes of Health, Bethesda, Md.

30. Results of this investigation were presented at the Annual Meeting of the Society for Pediatric Research in Washington, D.C., on May 3, 1974 .

31. Requests for reprints should be addressed to: A. B. Silken, M.D., Yale University School of Medicine, Department of Pediatrics, 333 Cedar St., New Haven, Conn. 06510 (USA).

32. Accepted for publication August 28, 1974. 